\title{
The Effects of Fluid Rheology and Drillstring Eccentricity on Drilling Hydraulics
}

\author{
Anthony Kerunwa, Julian Ubanozie Obibuike, Ugochukwu Ilozurike Duru, \\ Stanley Toochukwu Ekwueme \\ Federal University of Technology, Owerri, Nigeria \\ Email: anthonykerunwa@rocketmail.com, obibuikeubanozie@gmail.com,duruugoo@gmail.com, stanleyekwueme@yahoo.com
}

How to cite this paper: Kerunwa, A., Obibuike, J.U., Duru, U.I. and Ekwueme, S.T. (2021) The Effects of Fluid Rheology and Drillstring Eccentricity on Drilling Hydraulics. Open Journal of Yangtze Gas and Oil, 6, 129-145.

https://doi.org/10.4236/ojogas.2021.64012

Received: May 2, 2021

Accepted: October 16, 2021

Published: October 19, 2021

Copyright (C) 2021 by author(s) and Scientific Research Publishing Inc. This work is licensed under the Creative Commons Attribution International License (CC BY 4.0).

http://creativecommons.org/licenses/by/4.0/

\section{Abstract}

Accurate determination of hydraulic parameters such as pressure losses, equivalent circulation density (ECD), etc. plays profound roles in drilling, cementing and other well operations. Hydraulics characterization requires that all factors are considered as the neglect of any could become potential sources of errors that would be detrimental to the overall well operation. Drilling Hydraulics has been extensively treated in the literature. However, these works almost entirely rely on the assumption that the drill string lies perfectly at the center of the annulus-the so-called "concentric annulus". In reality, concentricity is almost never achieved even when centralizers are used. This is because of high well inclination angles and different string geometries. Thus, eccentricity exists in practical oil and gas wells especially horizontal and extended reach wells (ERWs) and must be accounted for. The prevalence of drillstring (DS) eccentricity in the annulus calls for a re-evaluation of existing hydraulic models. This study evaluates the effect of drilling fluid rheology types and DS eccentricity on the entire drilling hydraulics. Three non-Newtonian fluid models were analyzed, viz: Herschel Bulkley, power law and Bingham plastic models. From the results, it was observed that while power law and Bingham plastic models gave the upper and lower hydraulic values, Herschel Bulkley fluid model gave annular pressure loss (APL) and ECD values that fall between the upper and lower values and provide a better fit to the hydraulic data than power law and Bingham plastic fluids. Furthermore, analysis of annular eccentricity reveals that APLs and ECD decrease with an increase in DS eccentricity. Pressure loss reduction of more than 50\% was predicted for the fully eccentric case for Herschel Bulkley fluids. Thus, DS eccentricity must be fully considered during well planning and hydraulics designs.

\section{Keywords}

Wellbore, Drilling Fluid, String Geometries, Pressure Losses, Newtonian Fluid Models 


\section{Introduction}

Hydraulics plays vital roles in well operations such as drilling, cementing, completion, and well stimulation. Increasing well depth and complexity in geometry such as horizontal or extended reach wells (ERWs) gives rise to more complicated hydraulics than would be encountered in shallower slightly deviated or vertical wells. Proper study of hydraulics in a well is crucial as it translates to a reduction of risk, improvement in efficiency, decrease in the overall cost of well operation and reduction in non-productive time (NPT). Of all hydraulics encountered in well operations, drilling hydraulics is perhaps the most important because it covers more aspects in downhole operations than the others [1]. The aspects encountered in drilling hydraulics are downhole circulating pressures, surge and swab, equivalent circulation density (ECD), bit optimization, hole cleaning and volumetric displacement. Three basic factors affect drilling hydraulics in oil wells. These are the fluid, the hole and the drillstring (DS). Fluid could be Newtonian or non-Newtonian. Drilling fluids (DFs) are subjected to forces, downhole and they shear differently according to their rheological behaviour. Fluid rheology affects the character and deformation of DFs. Fluid rheology typically depends on the fluid type (whether Newtonian or non-Newtonian), flow regime (laminar or turbulent) and particle size distribution in the fluid (water-based or oil-based, inhibitive or non-inhibitive) [2] [3]. Fluid velocity, density, viscosity, size and shape of flow channel determine if the flow regime is laminar or turbulent or in a transition zone [4]. Fluid rheology helps to characterize fluid flow which helps in the determination of friction factors and frictional pressure losses (FPLs). Accurate knowledge of the FPL in the well helps to check against formation damage or fluid influx into the well. Oil well DFs are very sensitive to pressure and temperature conditions downhole, this makes fluid rheology an important factor in drilling hydraulics [5] [6]. Hole geometry affects the movement of fluids and rock particles in the well. In vertical wells, the influence of cuttings on drilling hydraulics is not profound. Cuttings deposition increases when wells deviate from vertical and become highest in horizontal wells [7] [8]. Cuttings deposit at the lower side of the well and require additional energy to displace them thereby increasing the friction factors and frictional pressures. Additionally, the hole condition also affects drilling hydraulics. If the hole is cased, then frictional pressure is not expected to be as high as when the well is open-hole. Open holes are noted with the presence of micro-doglegs and micro-tortuosities which increase the roughness of the hole and its frictional pressure [9]. The orientation of the pipe in the hole affects the flow pattern and hence its hydraulics in the well. Pipes in the hole can be concentric or eccentric depending on their placement in the hole. The pipe is said to be concentric when its axis coincides with the axis of the outer pipe or hole; otherwise, the pipe is said to be eccentric. Concentric pipes are usually modeled with less difficulty, but complexity in modeling increases as eccentricity increases [10]. Eccentric pipes in hole are usually the situation most encountered in reality. Eccentricity 
affects the pressure loss (PL) and fluid flow in the annuli. Over the years, many scholars have investigated the influence of pipe eccentricity on FPL in wellbores. [11] conducted one of the earliest works regarding pipe eccentricity. He provided analytical solution of Newtonian fluids in eccentric annuli. Later [12] developed a general equation for laminar flow of fluids in ducts of varied shapes. Their equations are used for calculating Reynolds numbers utilizing annular Poiseuille flow. [13] used numerical methods in evaluation of laminar flow of non-Newtonian fluids in eccentric annuli. He calculated the velocity profile, viscosity profile, flowrate vs FPL gradient for annulus of varying pipe eccentricities. He developed a correlation based on the model-generated data which helps in the easy calculation of PLs in the eccentric annuli. [14] presented correlations for power-law fluids for eccentric annuli. They utilized finite difference technique in numerically solving the laminar flow equation for Yield power-law fluids. They discovered that the velocity profile is substantially altered in the annulus when the inner pipe shifts from being concentric. [15] developed means to practically approximate flow through eccentric annuli. They achieved this by considering the annulus to be made up of infinite concentric annuli having variable annuli. This model neglects the circumferential shear force variation. [16] evaluated the effects of the rheological model, pipe eccentricity and equivalent roughness. They discovered that pipe eccentricity and roughness are vital parameters in the determination of PLs in the circulation of non-Newtonian fluids through the annulus. [17] provided numerical models for the laminar flow of yield power law fluids in eccentric annuli. They utilized finite differencing in solving the momentum equations. [18] [19] used experimental methods to evaluate the performance of Kozicki models for eccentric annuli. They called this model the pipe equivalent approach and suggested application of computational fluid dynamics (CFD) for a better results. [20] presented a means to calculate PLs in eccentric annuli. They based their study on an empirical definition of effective diameter which considers both geometry and rheology. They correlated pressure loss ratio (PLR) with pipe eccentricity, flowrate, rheology and rotational speed. [21] developed similar model to that of [20] but used field data. His model considered the effects of eccentricity on the rotational speed of DS. [22] made comparisons on the results of PL from CFD simulations and equivalent diameter method. They realized that CFD model gave a better performance. [23] used CFD in the investigation of the effect of pipe eccentricity on FPL. They considered the tangential velocity, axial velocity and effective viscosity of the fluid. [24] went further on the work of [21]. They used seven different definitions of equivalent diameter in the estimation of PL in eccentric annuli. They discovered the hydraulic diameter definition to be most essential in their study. [25] used CFD method to compute FPLs in eccentric annuli. They investigated the effects of flowrate, mud type and mesh size. They solved the problem using finite volume method. [26] analyzed the effect of eccentricity on PL and velocity profile. [27] noted that eccentricity effect in laminar flow is more profound than in tur- 
bulent flow. [6] used a CFD modeling approach to estimate FPLs in an eccentric annulus having inner pipe rotation. They considered this for the circulation of yield power law fluids. They considered eight fluids to have a wider range of dimensionless parameters. Their results agreed well with experimental data. Despite much literature studies on eccentricity, remarkable attention was not paid to the impacts of Fluid Rheology and DS eccentricity on the entire drilling hydraulics. In this study, Fluid Rheology and DS eccentricity effects on drilling hydraulics are investigated using well plan T\&D software. Field data for model validation were collected from Niger delta field.

\section{Pipe Eccentricity and Fluid Rheology}

\subsection{Pipe Eccentricity in Wellbore}

In reality, concentricity is almost never achieved as pipes tend to deviate from its center to one side of the wellbore. Sometimes centralizers are used to achieve a near-concentric annuli, this is the case with casing centralizers that are used to keep casings from contacting the wellbore. But even with the use of centralizers, the casing between centralizers could still deform leading to contact with the wellbore [28]. Centralization describes how off-centered a pipe is within another pipe or an Openhole. It is mainly expressed as a percentage. Thus a $0 \%$ eccentricity implies a concentric annulus while a $100 \%$ eccentricity implies that the pipes have contact with the outer pipe or wellbore. Centralization is important because it aids in casing wear studies and hole cleaning especially in the low side of the wellbore. In an eccentric annulus fluid preferentially flows through the wider annulus and thus there would be reduced velocity of fluid flow in the narrower annulus leading to build up of cutting beds due to gravity [7] [29]. As cuttings build up in the lower side of the annulus, hole cleaning becomes a problem and high tendency for pipe sticking exists. Research has shown that drill pipe eccentricity is affected by hole inclination angle, weight on bit and the size of the hole. Figure 1 depicts DS eccentricity in annulus.

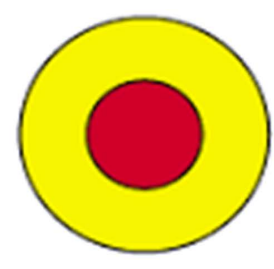

Concentric

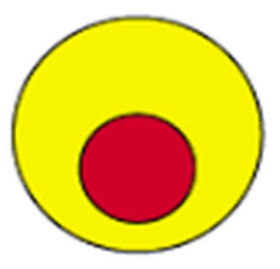

Partially eccentric

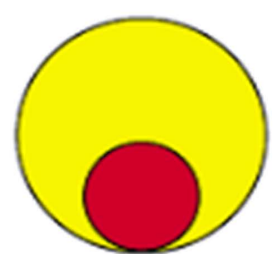

Fully eccentric

Figure 1. Drillstring eccentricity in annulus [29].

Well geometry and string stiffness plays profound part in annular eccentricity. In deviated wells, the DP should be fully eccentric over much of the deviated wellbore. In medium inclined sections of the deviated well, such as between $0^{\circ}$ $30^{\circ}$, the drill strings tend to lie on the high side of the wellbore. Meanwhile in 
high inclined sections or in horizontal wellbores, the DS lies on the lower side of the wellbore. Eccentricity will affect both the flow and the velocity distribution of fluids in the wellbore. It has been shown by research that the frictional pressure drop in an eccentric annulus is known to be less than the frictional pressure drop in a concentric annulus although this varies with fluid rheology type, the difference being much profound in Newtonian fluids than in non-Newtonian fluids [29]. Standoff is usually used to represent eccentricity expressed in percentage. An eccentricity of $100 \%$ implies a standoff of $0 \%$ and means that the inner pipe is in contact with the outer pipe or hole at the low side. Meanwhile, an eccentricity of $0 \%$ implies a standoff of $100 \%$ and means that the inner pipe is perfectly centered in the outer pipe or wall; this is a concentric situation [7].

\section{Equations for Eccentricity in Annulus}

Eccentricity in the annulus is given by the equation:

$$
\varepsilon=\frac{e}{c}=\frac{e}{r_{\mathrm{o}}-r_{\mathrm{i}}}
$$

where: $e=$ distance between the centers of inner and outer circle, inch

$\mathcal{E}=$ eccentricity ratio "the ratio of offset distance to radial clearance";

$r_{\mathrm{o}}=$ inner radius of outer pipe, inch;

$r_{\mathrm{i}}=$ outer radius of inner pipe, inch.

A correlation was developed by Salem and El-Din (2006) to determine the distance " $e$ " called $Y_{\max }$

$$
\begin{gathered}
\varepsilon=\frac{Y_{\max }}{r_{\mathrm{o}}-r_{\mathrm{i}}} \\
Y_{\max }=e \\
Y_{\max }=\frac{5.68 E I}{W_{\mathrm{b}} \cos \theta}\left(\left(\frac{0.176 W_{\mathrm{b}} \sin \theta(5.68 E I)^{0.5}}{E I\left(W_{b} \cos \theta\right)^{0.5}} \sinh \frac{\left(X\left(0.176 W_{\mathrm{b}} \cos \theta\right)^{0.5}\right)}{2(E I)^{0.5}}\right.\right. \\
\left.\left.-\frac{\left(0.176 W_{\mathrm{b}} \cos \theta\right)^{0.5}}{(E I)^{0.5}}\right)+\frac{0.5 X^{2} q \sin \theta}{4 E I}\right)
\end{gathered}
$$

$W_{\mathrm{b}}=$ weight on bit, (Ib), $E=$ modulus of elasticity, (psi), $\theta=$ hole inclination angle, (degree), $I=$ moment of inertia of the drill pipe (inch), $X=$ drill pipe horizontal projection, 1000 inches, $q$ = axial component of weight of drillpipe per unit length, $\mathrm{lb} / \mathrm{ft}$.

The pressure drop in eccentric annular flow is given as:

$$
\left[\frac{\mathrm{d} P_{\mathrm{f}}}{\mathrm{d} L}\right]_{\mathrm{e}}=C_{\mathrm{e}}\left[\frac{\mathrm{d} P_{\mathrm{f}}}{\mathrm{d} L}\right]_{\mathrm{c}}
$$

where $C_{\mathrm{e}}$ represents the correction factor for eccentricity.

$$
C_{\mathrm{e}}=f\left(\varepsilon, r_{\mathrm{i}} / r_{\mathrm{o}}, n, k, \tau_{\mathrm{o}}\right)
$$

where: $\mathcal{\varepsilon}=$ drill pipe eccentricity, $r_{\mathrm{i}} / r_{\mathrm{o}}=$ welbore parameter

$n, k, \tau_{\mathrm{o}}=$ fluid rheological parameters. 


\subsection{Fluid Rheology}

The rheology of the fluid affects its eccentricity values and hydraulics in general. Fluid rheology affects fluid shearing with the walls of the annulus or pipe [28]. Newtonian fluids behave differently from non-Newtonian fluids [30]. Most fluids used in well operations are adequately model as non-Newtonian fluids. These fluids have no direct proportionality between the shear stress and the shear rate unlike Newtonian fluids. Bingham plastic fluids became popular in usage in the oil industry because of its relative ease and simplicity of use in calculation of flow resistance and hydraulics. The disadvantage of the Bingham plastic fluid model is that it does not fully represent the behaviour of drilling fluids at low shear rates such as encountered in the annulus or at high shear rates such as encountered at the bits. Power law and Herschel Bulkley fluids models give a more definitive representation of practical drilling fluids in use today in oil and gas operations. However, Herschel Bulkley gained wider acceptance in usage because it accommodates yield point characteristics of Bingham plastics and the shear stress - shear rate characteristics of power law [28].

\subsubsection{Bingham Plastic Model}

The model for Bingham Plastic is characteristically defined by equation (7) below:

$$
\tau=\tau_{0}+\mu_{\mathrm{p}} \gamma
$$

Pressure loss calculation is done with reference to flow regime of the fluid. For Laminar flow, Pressure loss in the annulus using Bingham plastic model is given as

$$
\Delta P_{\mathrm{a}}=\left[\frac{\mu_{\mathrm{p}} v_{\mathrm{a}}}{1000\left(D_{2}-D_{1}\right)^{2}}+\frac{\tau_{\mathrm{y}}}{200\left(D_{2}-D_{1}\right)}\right] L_{\mathrm{a}}
$$

Similarly, for turbulent flow, Pressure loss in the annulus using Bingham plastic model is given as

$$
\Delta P_{\mathrm{a}}=\frac{f_{\mathrm{a}} \rho v_{\mathrm{a}}^{2}}{21.1\left(D_{2}-D_{1}\right)} L_{\mathrm{a}}
$$

\subsubsection{Power Law Model}

The equation for power law fluid model is given as

$$
\tau=K \gamma^{n}
$$

For laminar flow of power law fluids, the pressure drop in the annulus is calculated using the equation below

$$
\Delta P_{\mathrm{a}}=\frac{K_{\mathrm{a}} v_{\mathrm{a}}^{n_{\mathrm{a}}} L_{\mathrm{a}}}{144000\left(D_{2}-D_{1}\right)^{\left(1+n_{\mathrm{a}}\right)}}\left(\frac{2+\frac{1}{n_{\mathrm{a}}}}{0.0208}\right)^{n_{\mathrm{a}}}
$$

Moreover, for turbulent flow of power law fluids, the pressure drop in the annulus is calculated using the equation below. The pressure drop equation re- 
quires the determination of friction factor in the annulus for turbulent flow regime.

$$
\Delta P_{\mathrm{a}}=\frac{f_{\mathrm{a}} \rho v_{\mathrm{a}}^{2}}{25.8\left(D_{2}-D_{1}\right)} L_{\mathrm{a}}
$$

\subsubsection{Herschel Bulkley Fluid}

The equation that defines the behaviour of Herschel Bulkley fluids is given as

$$
\tau=\tau_{\mathrm{Y}}+K \gamma^{n}
$$

The yield stress for Herschel-Bulkley fluid is calculated at low shear rate and is given as

$$
\tau_{\mathrm{Y}}=2 \theta_{3}-\theta_{6}
$$

The pressure loss in the annulus for Herschel Bulkley fluids is given as

$$
\Delta P_{\mathrm{a}}=\frac{K_{\mathrm{a}} v_{\mathrm{a}}^{n_{\mathrm{a}}} L_{\mathrm{a}}}{144000\left(D_{2}-D_{1}\right)^{\left(1+n_{\mathrm{a}}\right)}}\left(\frac{2+\frac{1}{n_{\mathrm{a}}}}{0.0208}\right)^{n_{\mathrm{a}}}
$$

For turbulent flow, of Herschel Bulkley fluids in the annulus, annular friction factor is required. Thus, the equation that characterizes the pressure drop for turbulent flow of Herschel Bulkley fluids in the annulus is given by

$$
\Delta P_{\mathrm{a}}=\frac{f_{\mathrm{a}} \rho v_{\mathrm{a}}^{2}}{25.8\left(D_{2}-D_{1}\right)} L_{\mathrm{a}}
$$

\section{Case Study}

Well NDX2 is a well in the Niger Delta field and the well's drilling data are given below. The data was utilized for hydrauics simulation to determine the effect of Fluid rheology types and drillstring eccentricity on the hydralic parametres: annular pressure loss, ECD, gel breaking pressure, minimum flowrate of fluid. The well data are:

Fluid weight: $10.7 \mathrm{ppg}$;

Cased hole section: $95 / 8$ in OD, 8.65in ID, 47 ppf casing from top to $7254 \mathrm{ft}$, 8.625in OD, 7.63 in ID, $44 \mathrm{ppf}$ casing run from $7254 \mathrm{ft}$ to $9280 \mathrm{ft}$;

Open hole section: 7.25 in hole size with 0.3 OHFF;

Eccentricity ranges from concentric $(e=0)$ to various eeccentric annuli ( $e=$ 0.1 to $e=1.0$ ).

\section{Results and Discussions}

The results from the Wellplan T \& D simulation are given below for Herschel Bulkley, power law and Bingham Plastic fluid rheology models at various pipe eccentricities.

\subsection{Pressure Losses for Hershel Bulkley Fluid in Concentric Annulus}

The overall pressure losses when Herschel Bulkley fluid model was utilized are 
presented in Figure 2 for a concentric annulus. The system pressure loss comprises all the pressure losses experienced in the system from the surface to the bit. It includes the surface pressure losses if there is any, the string pressure losses (DS i.e. drill pipe, drill collar, etc.), the APLs, and bit pressure losses. The pressure loss estimation helps to know the pump size and horse power requirement for efficient pumping of fluid into the wellbore and controlled hydraulics operations. From Figure 2, the system pressure loss line touches the maximum pump pressure line at $527 \mathrm{gpm}$ pump rate. Thus to overcome the pressure losses prevalent in the system in pumping the fluid, the flowrate must be greater than $527 \mathrm{gpm}$. Generally, the pressure losses increase with increase in pump flowrate. The APL is the lowest; this is because of the wider annular space as compared to the bit or the DS. However, all the pressure losses in Figure 2 happen at the laminar flow regime.

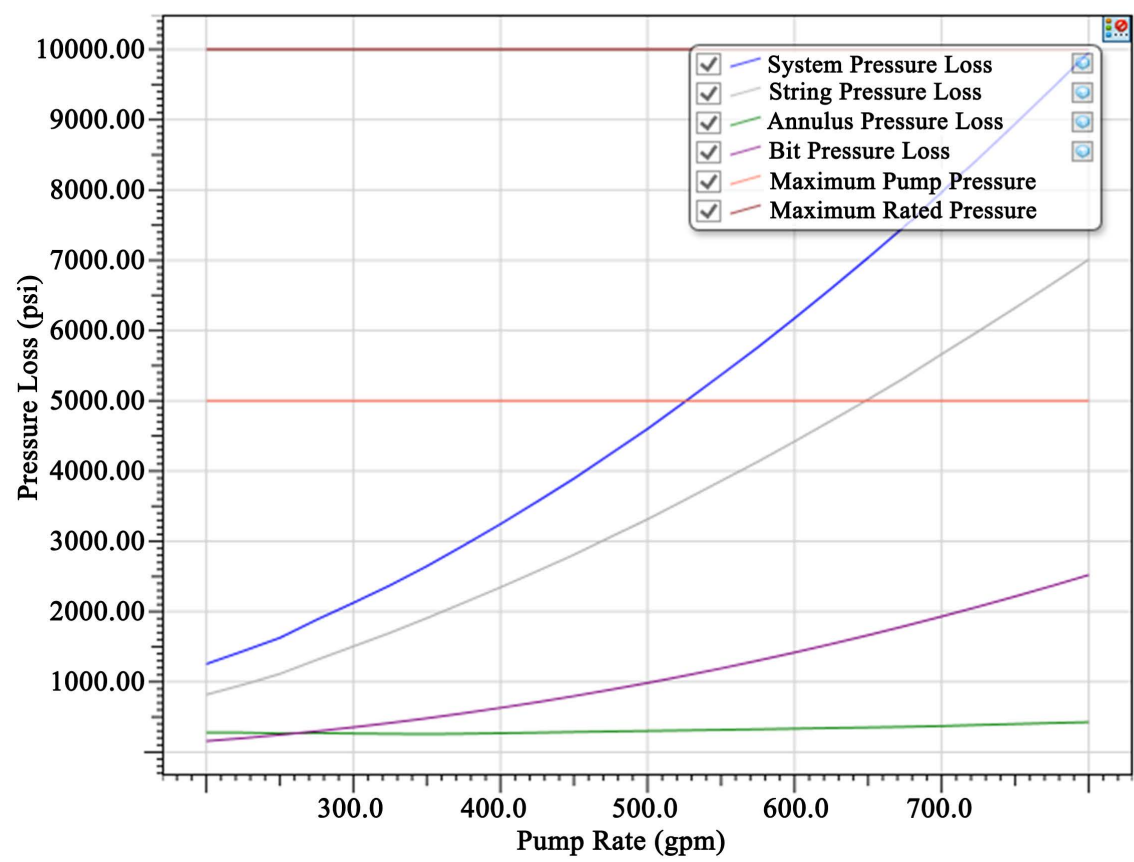

Figure 2. Pressure losses for Herschel Bulkley fluid for a concentric annulus as a Pump Rate function.

\subsection{Minimum Flowrate for Hershel Bulkley Fluid in Concentric Annulus}

Presented in Figure 3 is the minimum flowrate as a depth function for Herschel Bulkley fluid in a concentric annulus. This helps to determine the minimum or critical pump flow rate at which cuttings bed will begin to form. To avoid cuttings bed formation, it is required to maintain a flowrate at each particular depth greater than the minimum flowrate. The variation in minimum flowrate is a function of depth and geometry of strings at that depth. Therefore, cuttings will only be avoided if the flowrate is greater than the minimum flowrate at that depth. Because of the variation of minimum flowrate at each depth, the pump rate should be greater than the greatest minimum flowrate for the well. From the 
figure, the greatest minimum flowrate occurs at the last casing shoe which is at $9280 \mathrm{ft}$ and it corresponds to $398 \mathrm{gpm}$. Since ECD is the density of the DFs under dynamic conditions, ie when the pump is on and there is circulation. For the Hershel Bulkley fluid for concentric annulus, the ECD at casing shoe is 11.24 ppg and at the bit it is $11.36 \mathrm{ppg}$. Thus the ECD both at the shoe and at the bit is considerably higher than the static mud weight which is 10.7 ppg. Knowledge of ECD is therefore important in that it helps to avoid fracture of the formation during circulation because the mud appears to have greater weight.

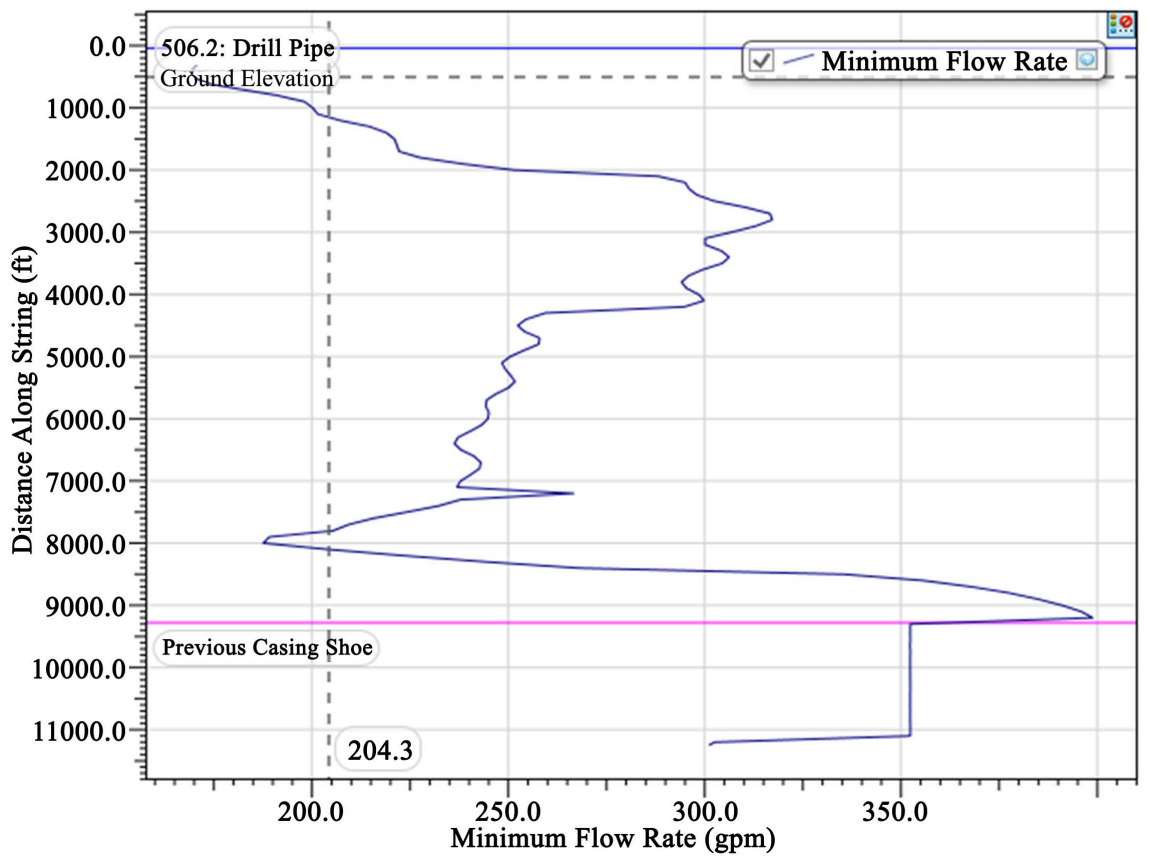

Figure 3. Minimum flowrate as a depth function for Herschel Bulkley fluid in a concentric annulus.

\subsection{Effect of Pipe Eccentricity on APL for Hershel Bulkley Fluid}

Eccentricity affects APLs because of variations in annular flow area called the radial clearance. Higher drill string eccentricity entails higher flow area. Since pressure is indirectly proportional to area, conduits with greater area will have lesser pressure. Thus, it is expected that eccentric annuli will have less annular pressure drop than concentric annuli. This being the case, then APL should decrease with increasing drill string eccentricity and the lowest annular pressure drop should occur when the drill string touches the wellbore (fully eccentric case). Depicted in Figure 4 is the APL for Hershel Bulkley fluid at various pipe eccentricities. From Figure 4, it can be observed that the highest APL occurs when eccentricity is zero, i.e. when the DS is concentric in the annulus. The green line at the top most part of the plot represents the APL profile for concentric annulus. Conversely, the APL begins to decrease with increasing eccentricities from 0.1 to 1.0. At 1.0, the APL becomes lowest. The dark blue line at the bottom of the plot represents the annular pressure profile for Herschel Bulkley fluid for fully eccentric annulus. The result from Figure 4 show that APL de- 
creases with increasing DS eccentricities. The highest annular pressure drop was witnessed for a concentric annulus $(e=0)$. The lowest APL was seen at a fully eccentric annulus $(e=1.0)$. Cuttings bed formation due to gravity forces pulled cuttings to the lower sides of the hole. These cuttings bed proves difficult to clean and may result to severe well problem. [31] averred that these drilled cuttings and gelled DF are best removed through pipe rotation in narrow annulus. This is due to the fact that, in eccentric annulus, if there is no pipe rotation the DF will preferentially flow through wider annulus.

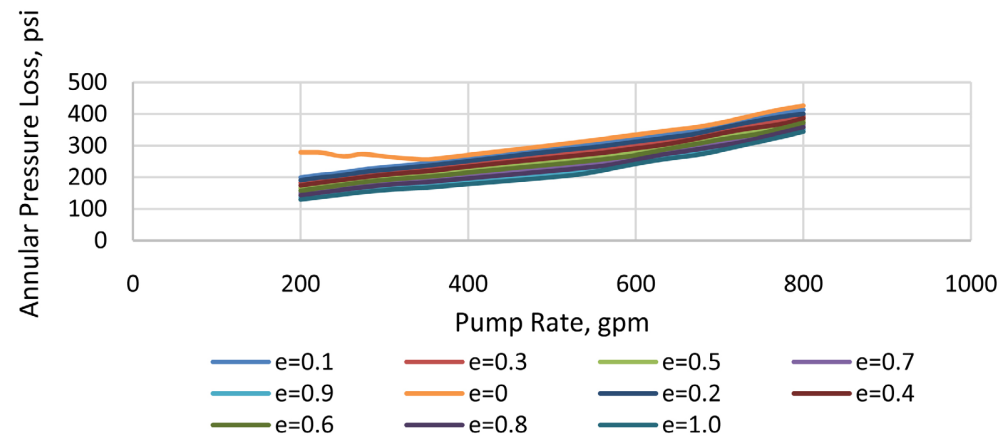

Figure 4. APL for Hershel Bulkley fluid at various pipe eccentricities.

[32] posited that pipe rotation creates rotational effect with an induced turbulence and this forces the drilled cuttings and gelled DF out of the narrow annulus. Figure 5 shows the percentage decrease to DS eccentricity in the annulus. It can be seen from the figure that at $200 \mathrm{gpm}$, there is up to $54 \%$ percentage decrease in APL due to full eccentricity from the initial concentric annulus. The lowest percentage decrease is seen at $800 \mathrm{gpm}$ which is $19.2 \%$ decrease. It can be observed from Figure 5 also that decrease in APL due to increasing eccentricity gets smaller as flowrate increases. Thus, Eccentricity is important in estimation of the APL because more than $50 \%$ reduction is achievable to eccentricity of the annulus. Figure 5 shows that more than $50 \%$ reduction was realized for a change to fully eccentric annulus. The reason for the reduction in APL is because of the increase in flow area given by the increased radial clearance in the annulus. APL is inversely proportional to the radial clearance. The higher the annular radial clearance, the less the annular pressure drops.

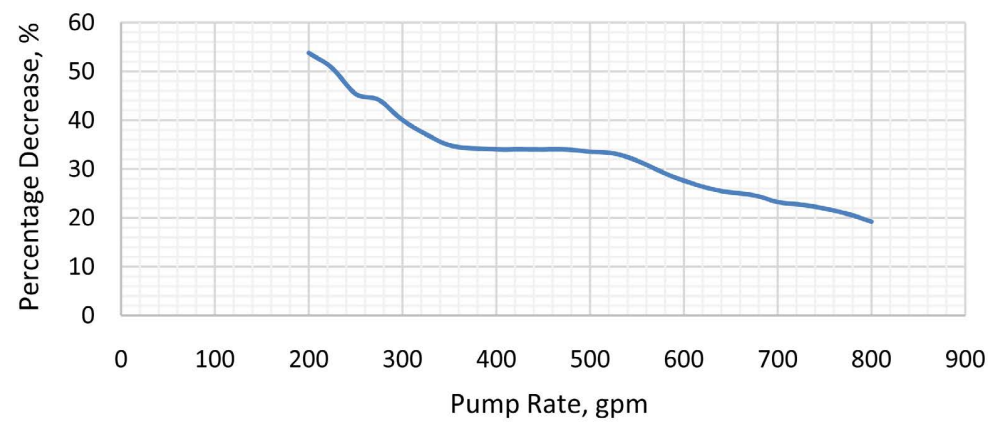

Figure 5. Percentage Decrease from concentric to full eccentric annulus on Herschel Bulkley fluids. 


\subsection{Effect of Pipe Eccentricity on ECD for Hershel Bulkley Fluid}

Depicted in Table 1 is the ECD for various eccentricities. From Table 1, it can be observed that the highest ECD both at the shoe and at the bit occurs when the eccentricity is zero (concentric annulus) and the lowest ECD both at the shoe and at the bit occurs when the eccentricity is 1.0 (Fully eccentric annulus). A closer look at the table reveals that ECD decreases with increase in DS eccentricity in the annulus.

Table 1. ECD at various annulus eccentricity for Herschel Bulkley fluid model.

\begin{tabular}{lllllllllllll}
\hline Parameter & $e=0$ & $e=0.1$ & $e=0.2$ & $e=0.3$ & $e=0.4$ & $e=0.5$ & $e=0.6$ & $e=0.7$ & $e=0.8$ & $e=0.9$ & $e=1.0$ \\
\hline $\begin{array}{c}\text { ECD at shoe, } \\
\text { ppg }\end{array}$ & 11.24 & 11.2 & 11.18 & 11.16 & 11.13 & 11.11 & 11.09 & 11.07 & 11.05 & 11.02 & 11 \\
$\begin{array}{c}\text { ECD at bit, } \\
\text { ppg }\end{array}$ & 11.36 & 11.32 & 11.3 & 11.28 & 11.25 & 11.23 & 11.21 & 11.19 & 11.17 & 11.14 & 11.12 \\
\hline
\end{tabular}

\subsection{APLs for Various Fluid Rheology Types}

Depicted in Figure 6 are the APLs in the laminar flow regime for Herschel Bulkley, power law and Bingham Plastic fluids rheology types. From the figure, it can be observed that Bingham plastic fluid has higher pressure losses for lower fluid pump rates. The pressure losses for Bingham plastic fluid is greater than those of other rheology types considered until 275 gpm. Beyond $275 \mathrm{gpm}$, power law fluids show higher APL as a function of the fluid pump rate. Power law show higher APLs from $275 \mathrm{gpm}$ to $725 \mathrm{gpm}$. From $725 \mathrm{gpm}$ above, Bingham plastic fluids again shows greater APLs for pump rates. It can be seen that Hershel Bulkley fluids is almost in-between the Bingham plastic and power law fluids. At low and higher pump rates, Bingham plastic model overestimates the APLs and underestimates the APLs for moderate flowrate while power law fluids underestimates the APLs for low and higher pump rate but overestimates it for moderate pump rates. However Hershel Bulkley models falls between the upper and lower boundaries of the pressure losses and represents the best fit for the data.

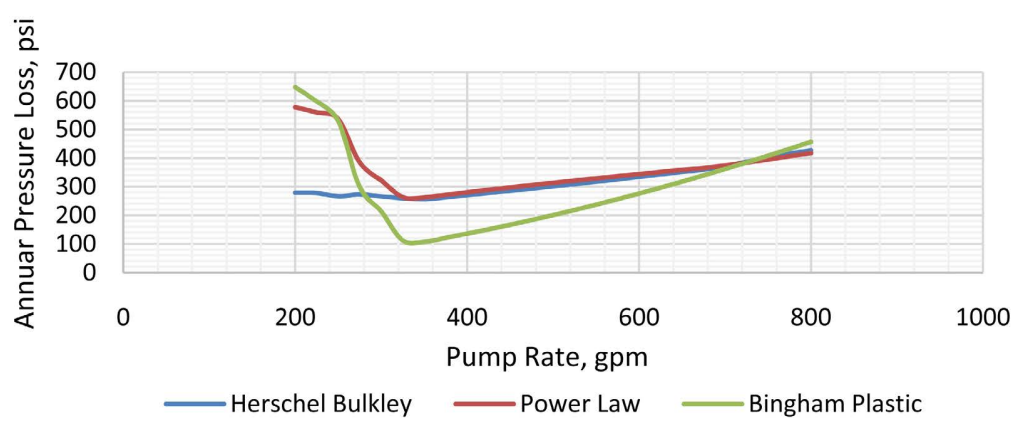

Figure 6. APLs as a Pump Rate function for concentric annulus for various fluids rheology types.

\subsection{Minimum Flowrate for Various Rheology Types}

Depicted in Figure 7 is the minimum flowrate as a depth function for concentric 
annulus for Herschel Bulkley, power law and Bingham Plastic fluids rheology types. From Figure 7, it can be observed that the Herschel Bulkley model gives more minimum annular flowrate than Bingham plastic and power law fluids. Thus, higher flowrate is required to prevent cuttings bed build up in Herschel Bulkley fluids (for pump rates of $250 \mathrm{gpm}$ and above) than in Bingham plastic and power law fluids. Figure 7 shows the minimum flowrate. The minimum flowrate represent the lowest flowrate needed to prevent the buildup of cuttings bed in the wellbore. Analyses of Figure 7 reveal that higher flowrate is required for Hershel Bulkley fluids to avoid the formation of cuttings bed. Cuttings deposition increases the frictional pressure drop in the annulus and may lead to severe well problem such as stuck pipe which translates to huge financial involvement to remedy and requires pipie rotation to clean up as pointed out by [31]. When circulating Herschel Bulkley fluids, care must be taken to circulate at higher pump rates in order to avoid the formation of cuttings bed.

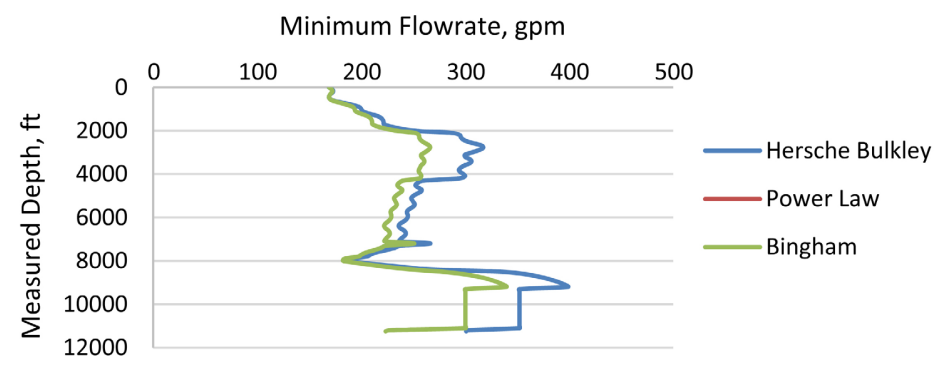

Figure 7. Minimum flowrate as a depth function for concentric annulus for various fluids rheology types.

\subsection{ECD for Various Rheology Types}

Table 2 shows the ECD for various fluids rheology types. It can be observed that Bingham plastic model gives the lowest ECD at the shoe and at the bit. Power law fluid gave the highest ECD values at the shoe and at the bit. Herschel Bulkley fluids falls between the upper and lower values gotten from the power law and Bingham plastic fluid models respectively. It can be observed that fluid rheology affects the ECD. Herschel Bulkley model gives ECD value that falls between the Power law and the Bingham plastic model. This result is in consonance with the definition of Herschel Bulkley fluids that incorporates the low shear rates of Bingham plastic fluids and the shear stress-shear rate of power law fluids. Thus Hershel Bulkley model being a three-parameter model compensates for the inabilities of power law and Bingham plastic models and gives a better match to field data.

Table 2. ECD for concentric annulus for different rheological models.

\begin{tabular}{ccc}
\hline Rheology type & ECD at shoe, ppg & ECD at bit, ppg \\
\hline Hershel Bulkley & 11.24 & 11.36 \\
Power Law & 11.26 & 11.38 \\
Bingham Plastic & 10.97 & 11.04 \\
\hline
\end{tabular}




\section{Conclusions}

The following conclusion is drawn from this study:

1) Drill pipe eccentricity leads to reduction of APLs;

2) ECD decreases with increasing eccentricity;

3) Bingham plastic and power law fluids give the lowest and highest ECD values respectively;

4) Drill string eccentricity has a considerable effect on APLs while circulating Herschel Bulkley fluids. Pressure loss reduction of more than $50 \%$ was predicted for the fully eccentric case. Thus, DS eccentricity must be fully considered during drilling hydraulics planning and designs. The case is more severe in horizontal and extended reach wells where high DS eccentricities are expected;

5) Hershel Bulkley fluids require more flowrate to prevent cuttings removal than Bingham plastic and power law fluids;

6) Hershel Bulkley fluid model gives a more representative match on practical DFs than Bingham plastic and power law fluids in the estimation of APLs.

\section{Conflicts of Interest}

The authors declare no conflicts of interest regarding the publication of this paper.

\section{References}

[1] Ochoa, M.A. (2006) Analysis of Drilling Fluid Rheology and Tool Joint Effect to Reduce Errors in Hydraulics Calculations. PhD Thesis, Texas A\&M University, Texas.

[2] Ahmed, R. and Miska, S. (2008) Study and Modeling of Yield Power-Law Fluid Flow in Annuli with Drillpipe Rotation. Paper Presented at the IADC/SPE Drilling Conference, Orlando, March 2008, Paper No. SPE 112604. https://doi.org/10.2118/112604-MS

[3] Ahmed, R., Miska, S.Z. (2009) Chapter 4.1. Advanced Wellbore Hydraulics. In: Aadnoy, B., Cooper, I., Miska, S., Mitchell, R.F. and Payne, M.L., Eds., Advanced Drilling and Well Technology, Society of Petroleum Engineers, Richardson, TX, 191-219.

[4] Hemphill, T., Campos W. and Pilehvari A. (1993) Yield-Power Law Model More Accurately Predicts Mud Rheology. Oil \& Gas Journal, 91, 45-50.

[5] Erge, O., Karimi V.A, Ozbayoglu, E.M. and Oort, E. (2016) Improved ECD Prediction and Management in Horizontal and Extended Reach Wells with Eccentric Drillstrings. Paper Presented at the IADC/SPE Drilling Conference and Exhibition, Fort Worth, March 2016, Paper No. SPE-178785-MS.

https://doi.org/10.2118/178785-MS

[6] Erge, O., Ozbayoglu, E.M., Miska, S.Z., Yu, M., Takach, N., Saasen, A. and May, R. (2016) Equivalent Circulating Density Modeling of Yield Power Law Fluids Validated with CFD Approach. Journal of Petroleum Science and Engineering, 140, 16-27. https://doi.org/10.1016/j.petrol.2015.12.027

[7] Erge, O., Ozbayoglu, E. M., Miska, S. Z., Yu, M., Takach, N., Saasen, A., May, R. (2014) Effects of Drillstring Eccentricity, Rotation and Buckling Configurations on Annular Frictional Pressure Losses While Circulating Yield Power Law Fluids. SPE 
Drilling \& Completion, 30, 257-271. https://doi.org/10.2118/167950-PA

[8] Kerunwa, A. (2020) Contributory Influence of Drill Cuttings on Equivalent Circulation Density Model in Deviated Wellbores. International Journal of Oil, Gas and Coal Engineering, 8, 82-90. https://doi.org/10.11648/j.ogce.20200804.12

[9] Erge, O., Ozbayoglu, E. M., Miska, S. Z., Yu, M., Takach, N., Saasen, A. and May, R. (2015) Analysis and Model Comparison of Annular Frictional Pressure Losses While Circulating Yield Power Law Fluids. Paper Presented at the SPE Bergen One Day Seminar, Bergen, April 2015, Paper No. SPE 173840. https://doi.org/10.2118/173840-MS

[10] Hansen, S.A. and Sterri, N. (1995) Drill Pipe Rotation Effects on Frictional Pressure Losses in Slim Annuli. Paper Presented at the SPE Annual Technical Conference and Exhibition, Dallas, October 1995, Paper No. SPE 30488. https://doi.org/10.2118/30488-MS

[11] Piercy, N.A.V., Hooper, M.S. and Winny, H.F. (1933) Viscous Flow through Pipes with Core. The London, Edinburgh, and Dublin Philosophical Magazine and Journal of Science, 15, 647-676. https://doi.org/10.1080/14786443309462212

[12] Kozicki, W., Chou, C.H. and Tiu, C. (1966) Newtonian Flow in Ducts of Arbitrary Cross-Sectional Shape. Chemical Engineering Science, 21, 665-679. https://doi.org/10.1016/0009-2509(66)80016-7

[13] Haciislamoglu, M. (1989) Non-Newtonian Fluid Flow in Eccentric Annuli and Its Application to Petroleum Engineering Problems. Ph.D Dissertation, Louisiana State University, Baton Rouge, LA.

[14] Haciislamoglu, M. and Langlinais, J. (1990) Non-Newtonian Flow in Eccentric Annuli. Journal of Energy Resources Technology, 112, 163-169. https://doi.org/10.1115/1.2905753

[15] Luo, Y. and Peden, J.M. (1990) Flow of Non-Newtonian Fluids through Eccentric Annuli. SPE Production Engineering, 5, 91-96. https://doi.org/10.2118/16692-PA

[16] Subramanian, R. and Azar, J.J. (2000) Experimental Study on Friction Pressure Drop for NonNewtonian Drilling Fluids in Pipe and Annular Flow. Paper Presented at the International Oil and Gas Conference and Exhibition in China, Beijing, November 2000, Paper No. SPE-64647-MS. https://doi.org/10.2118/64647-MS

[17] Adariani, H.Y. (2005) Simulation of Laminar Flow of Non-Newtonian Fluids in Eccentric Annuli. M.Sc. Thesis, University of Tulsa, Tulsa.

[18] Sestak, J., Zitny, R., Ondrusova J. and Filip, V. (2001) Axial Flow of Purely Viscous Fluids in Eccentric Annuli: Geometric Parameters for Most Frequently Used Approximate Procedures. 3rd Pacific Rim Conference on Rheology, Vancouver, 8-13 July, 1-3.

[19] Ahmed, R., Miska, S.Z. and Miska, W.Z. (2006) Friction Pressure Loss Determination of Yield Power Law Fluid in Eccentric Annular Laminar Flow. Wiertnictwo Nafta Gaz, 23, 47-53.

[20] Pilehvari, A. and Serth, R. (2009) Generalized Hydraulic Calculation Method for Axial Flow of NonNewtonian Fluids in Eccentric Annuli. SPE Drilling \& Completion, No. 24, 553-563. https://doi.org/10.2118/111514-PA

[21] Ahmed, R.M., Enfis, M.S., El Kheir, H.M., Laget, M. and Saasen, A. (2010) The Effect of Drillstring Rotation on Equivalent Circulation Density: Modeling and Analysis of Field Measurements. Paper Presented at the SPE Annual Technical Conference and Exhibition, Florence, September 2010, Paper SPE 135587. https://doi.org/10.2118/135587-MS

[22] Sorgun, M. and Ozbayoglu, M. E. (2011) Predicting Frictional Pressure Loss during 
Horizontal Drilling for Non-Newtonian Fluids. Energy Sources, Part A: Recovery, Utilization, and Environmental Effects, 33, 631-640.

https://doi.org/10.1080/15567030903226264

[23] Sorgun, M. (2011) Computational Fluid Dynamics Modeling of Pipe Eccentricity Effect on Flow Characteristics of Newtonian and Non-Newtonian Fluids. Energy Sources, Part A: Recovery, Utilization, and Environmental Effects, 33, 1196-1208. https://doi.org/10.1080/15567036.2010.492381

[24] Anifowoshe, O.L. and Osisanya, S.O. (2012) The Effect of Equivalent Diameter De finitions on Frictional Pressure Loss Estimation in an Annulus with Pipe Rotation. Paper Presented at the SPE Deepwater Drilling and Completions Conference, Galveston, June 2012, Paper No. SPE 151176. https://doi.org/10.2118/151176-MS

[25] Vajargah, A.K. and Oort, E.V. (2015) Automated Drilling Fluid Rheology Characterization with Downhole Pressure Sensor Data. Paper Presented at the SPE/IADC Drilling Conference and Exhibition, London, Paper No. SPE 173085. https://doi.org/10.2118/173085-MS

[26] Mokhtari, M., Ermila, M. and Tutuncu, A.N. (2012) Accurate Bottomhole Pressure for Fracture Gradient Prediction and Drilling Fluid Pressure Program-Part I. 46th U.S. Rock Mechanics/Geomechanics Symposium, Vol. ARMA-2012-235, Chicago, 24-27 June 2012, 1-14.

[27] Vajargah, A.K. and Oort, E.V. (2015) Determination of Drilling Fluid Rheology under Downhole Conditions by Using Real-Time Distributed Pressure Data. Journal of Natural Gas Science and Engineering, 24, 400-411.

https://doi.org/10.1016/j.jngse.2015.04.004

[28] Kristensen, A. (2013) Flow Properties of Water-Based Drilling Fluids. Master's Thesis, Norwegian University of Science and Technology, Trondheim.

[29] Akrong, J.A. (2010) Effect of Pipe Eccentricity on Hole Cleaning and Wellbore Hy draulics. Master's Thesis, African University of Science and Technology, Abuja.

[30] Kerunwa, A. (2020) Drillstring Buckling Prediction and its Impact on Tool-Joint Effects in Extended Reach Wells. International Journal of Oil, Gas and Coal Engineering, 8, 157-166. https://doi.org/10.11648/j.ogce.20200806.16

[31] Hemphill, T. and Ravi K. (2006) Pipe Rotation and Hole Cleaning in an Eccentric Annulus. Paper Presented at 2006 IADC/SPE, Miami, Florida, 21-23 February, Paper No. SPE 99150.

[32] Pereira, F.A.R., Ataíde, C.H. and Barrozo, M.A.S. (2010) CFD Approach Using a Discrete Phase Model for Annular Flow Analysis. Latin American Applied Research, 40, 53-60. 


\section{Appendix}

Table A1. String data.

\begin{tabular}{|c|c|c|c|c|c|c|c|c|c|c|c|c|}
\hline \multirow{3}{*}{ Type } & \multicolumn{2}{|c|}{ Length } & \multicolumn{2}{|c|}{ Body } & \multicolumn{3}{|c|}{ STB/Tool Joint } & \multicolumn{2}{|c|}{ Linear Weight } & \multirow{2}{*}{ Grade } & \multirow{3}{*}{ Material } & \multirow{3}{*}{ Class } \\
\hline & Pipe & Total & OD & ID & OD & ID & Length & NOM & Actual & & & \\
\hline & {$[\mathrm{ft}]$} & {$[\mathrm{ft}]$} & [in] & [in] & [in] & [in] & [in] & {$[\mathrm{lb} / \mathrm{ft}]$} & {$[\mathrm{lb} / \mathrm{ft}]$} & [psi] & & \\
\hline BIT & 0.66 & 0.66 & 6.00 & 0.00 & - & - & & 0.00 & 0.00 & 0 & CS & \\
\hline PDM & 26.25 & 26.90 & 4.75 & 2.00 & - & - & 29.9 & 42.91 & 42.91 & 110,000 & CS & \\
\hline Stabilizer & 1.15 & 28.05 & 4.75 & 2.25 & 5.75 & 2.19 & 3.3 & 40.00 & 40.00 & 110,000 & CS & \\
\hline Hevi-Wate DP & 10.17 & 38.22 & 3.50 & 2.25 & 4.75 & 2.188 & 20 & 25.00 & 25.00 & 55,000 & CS & \\
\hline MWD & 61.35 & 99.57 & 4.75 & 1.92 & - & - & 29.9 & 50.00 & 50.00 & 110,000 & SS & \\
\hline Hevi-Wate DP & 30.51 & 130.09 & 3.50 & 2.06 & 4.75 & 2.125 & 20 & 25.00 & 25.00 & 55,000 & CS & \\
\hline Drill Pipe & 2577.76 & 2707.84 & 3.50 & 2.76 & 4.812 & 2.125 & 29.9 & 13.30 & 13.30 & 135,000 & CS & $\mathrm{P}$ \\
\hline Hevi-Wate DP & 367.29 & 3075.13 & 3.50 & 2.25 & 4.75 & 2.313 & 20 & 23.20 & 23.20 & 55,000 & CS & \\
\hline Jar & 12.50 & 3087.63 & 4.75 & 2.06 & - & - & 20 & 37.50 & 37.50 & 110,000 & CS & \\
\hline Hevi-Wate DP & 1010.14 & 4097.77 & 3.50 & 2.25 & 4.75 & 2.313 & 20 & 23.20 & 23.20 & 55,000 & CS & \\
\hline Hevi-Wate DP & 370.73 & 4468.50 & 5.00 & 3.00 & 6.5 & 3 & 20 & 49.70 & 49.70 & 55,000 & CS & \\
\hline Drill Pipe & 6780.94 & $11,249.44$ & 5.00 & 4.28 & 6.312 & 2.75 & 28.9 & 19.50 & 19.50 & 135,000 & CS & $\mathrm{P}$ \\
\hline
\end{tabular}

\section{Nomenclature}

ECD_Equivalent circulation density

ERW-Extended reach well

ERWs-Extended reach wells

APL-Annular pressure loss

APLs-Annular pressure losses

DF-Drilling fluid

DS-Drillstring

FPL_Frictional pressure loss

FPLs-Frictional pressure losses

$\tau=$ shear stress, $\mathrm{lb} / \mathrm{ft}^{2}$

$\tau_{0}=$ Yield stress in $\mathrm{lb} / \mathrm{ft}^{2}$

$\mu_{\mathrm{p}}=$ Plastic viscosity, $\mathrm{cp}$

$n=$ flow behavior index

$\tau_{\mathrm{y}}=$ Yield stress in $\mathrm{lb} / \mathrm{ft}^{2}$

$\gamma=$ Shear rate

$K=$ Consistency index

$\Delta P_{\mathrm{a}}=$ Pressure loss for the annulus interval, $\mathrm{psi}$

$L_{\mathrm{a}}=$ Length of the annulus interval, $\mathrm{ft}$

$f_{\mathrm{a}}=$ friction factor in the annulus

$\left(D_{2}-D_{1}\right)=$ anuular space, in

$D_{2}=$ hole diameter or casing internal diameter

$D_{1}=$ Pipe or drill collar inside diameter, in 
$n_{\mathrm{a}}=$ Flow behavior index for the annulus (dimensionless)

$\theta_{6}=$ Viscometer reading at $6 \mathrm{rpm}$

$\theta_{3}=$ Viscometer reading at $3 \mathrm{rpm}$

$K_{\mathrm{a}}=$ Consistency factor in the annulus $\mathrm{cP}$

$V_{\mathrm{a}}=$ Fluid velocity in the annulus, $\mathrm{ft} / \mathrm{s}$ 